\title{
Os milagres de Cristo no Quarto Evangelho como símbolo da miserieórdia de Deus
}

\section{The miracles of Christ in the Fourth Gospel as a symbol of God's mercy}

\author{
Élcio Bernardino Correia*
}

Recebido: 27/06/2017. Aprovado: 25/11/2017.

Resumo: Este artigo tem como propósito apresentar uma análise dos milagres de Cristo no Quarto Evangelho a partir do ponto de vista da misericórdia divina. $O$ objetivo é mostrar que tanto as ações quanto a atitude de Cristo no desempenho de seus milagres refletem um retrato do Deus misericordioso de maneira singular. A metodologia usada será a de uma breve apresentação do termo hesed (7ơ) na Bíblia Hebraica e uma análise sintética dos sinais de Cristo no Evangelho como símbolo da misericórdia. Conclui-se que Jesus demonstra nos sinais de seu ministério, com precisão inequívoca, o atributo da misericórdia de Deus.

Palavras-chave: Misericórdia. Sinais. Quarto Evangelho. Milagres.

Abstract: This article aims to present an analysis of the miracles of Christ in the Fourth Gospel from the point of view of divine mercy. The purpose is to show that both the actions and the attitude of Christ in the performance of his miracles reflect a picture of the merciful God in a unique way. The methodology used will be a brief presentation of the term hesed (non) in the Hebrew Bible and a synthetic analysis of the signs of Christ in the Gospel as a symbol of mercy. It follows that Jesus shows in the signs of his ministry with unmistakable precision the attribute of God's mercy.

Keywords: Mercy. Signs. Fourth Gospel. Miracles.

\section{Introdução}

Diante da aproximação do cinquentenário da Conferência Geral de Medellin, em 1968, podemos lembrar inicialmente uma importante

* Mestre em Teologia (PUC-SP, São Paulo, 2015). Integrante do grupo LIJO (grupo de pesquisa sobre Literatura Joanina) da PUC-SP, pelo CNPQ. Professor de Teologia Sistemática, Homilética e Hebraico Bíblico no Seminário Batista Logos de São Paulo.

E-mail: angellos@ig.com.br 
citação do documento: "A Igreja da América Latina, dadas as condições de pobreza e subdesenvolvimento do continente, sente a urgência de traduzir esse espírito de pobreza em gestos, atitudes e normas, que a tornem um sinal mais lúcido e autêntico do Senhor"1. Notadamente o documento aponta o referencial "sinal mais lúcido e autêntico do Senhor" como gestos concretos da missão e ação da Igreja diante dos excluídos.

O Quarto Evangelho apresenta o Cristo que potencializa a ação de Deus para todos de uma maneira exponencial (cf. Jo 3,16). Um recurso usado de forma recorrente no Evangelho de João é o uso dos sinais/ milagres que por sua vez sempre apontam para o Pai e a para a vida (cf. Jo 20,31). O Evangelho segundo João deixa claro que o Cristo é o ápice da revelação de Deus (cf. Jo 1,18). Note-se que o vocábulo empregado

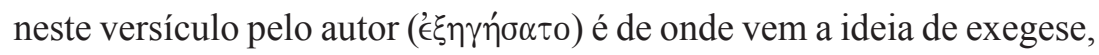
de interpretação. Cristo portanto é o retrato, a interpretação precisa da pessoa de Deus, tanto é que Ele mesmo afirma reiteradamente sua unidade com o Pai (cf. Jo 8,19; 10,30.38; 14,7-11). Mas se Jesus é o referencial de Deus, como Este se mostra nas tradições de Israel?

\section{Deus misericordioso no antigo testamento}

Entre todos os termos que poderíamos analisar afim de descrever a misericórdia de Deus, o mais abrangente e emblemático é hesed (חסֶ). Girdlestone ${ }^{2}$ diz que este termo hebraico é usado profusamente no Antigo Testamento tanto para descrever o lidar de Deus para com o homem como para a ação do homem para com o seu próximo.

Esser $^{3}$ afirma que a LXX traduz hesed (חס) recorrentemente pelo termo grego éleos ( $\left.{ }^{\prime} \lambda \in O \varsigma\right)$. Este mesmo autor diz que em geral as traduções do hebraico e grego vertem o termo como misericórdia, piedade, favor, bondade, afeição. Frequentemente o vocábulo está unido com justiça, fidelidade, verdade, compaixão e outras qualidades divinas.

1 CONFERÊNCIA DO EPISCOPADO LATINO-AMERICANO. Conclusões de Medellin. 4. ed. São Paulo: Paulinas, 1979. p. 146.

2 GIRDLESTONE, R. B. Synonyms of the Old Testament. Grand Rapids: W. B. Eerdmans Publishing Company, 1986. p. 111-116.

3 ESSER, H. H. Misericórdia. Em BROWN, C.; COENEN, L. (Orgs). Dicionário Internacional de Teologia do NT, VI III. São Paulo: Vida Nova, 1985. p.177. 
Schökel1 ${ }^{4}$ assevera que os dois aspectos fundamentais do termo hesed (חסֶ) são a misericórdia, ou seja o aspecto gratuito da benevolência, e a lealdade que resulta no compromisso. A mesma obra destaca a abrangência semântica do termo, porque hesed (סְ̣) pode ser usada de forma variada e ainda associada com nomes, por exemplo misericórdia e verdade ou misericórdia verdadeira.

Lucena descreve o uso do termo da seguinte forma:

Nos livros do AT, este termo foi usado na esfera das relações humanas, para descrever a relação íntima entre parentes ou amigos, a relação entre soberano e súbditos ou entre duas partes antagônicas. No âmbito mais íntimo, (דơ) manifestava-se na ajuda ou num gesto de bondade para com um familiar ou amigo. Na relação entre pessoas com pouca intimidade, expressava-se através de um gesto de bondade inesperado, ou na intervenção a favor de alguém que estivesse a sofrer: a libertação de um prisioneiro ou a hospitalidade a um estrangeiro. A um dado momento deu-se a expansão do conceito de (דon) da esfera secular e privada, para a esfera religiosa. Para o povo de Israel isso aconteceu a partir do momento em que ele se reconheceu como o povo eleito de Deus, com quem celebrou uma Aliança. ${ }^{5}$

Assim, em diversas passagens veterotestamentárias, Deus é retratado como Aquele que demonstra misericórdia (cf. Gn 24,12.27; 39,21; Ex 20,6; 34,6; Nm 14,19; Dt 4,31; Ne 9,31; S1 5,7; 6,4; 13,5; 119,88; Jr 31,3.20; J1 2,13; Is 63,7.9; Jn 4,2; Mq 7,18). Mas a misericórdia vai além das ações de Deus e transborda em seu próprio ser. Desta forma hesed (7оח) também é empregada de forma adjetiva em relação a Deus (cf. Sl $4,3 ; 30,4 ; 86,2 ; 145,17)$. E "O Senhor é misericordioso e compassivo,

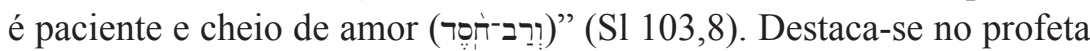
Jeremias tanto as ações misericordiosas de Deus (cf. Lm 3,22-23) quanto a afirmação divina de que a misericórdia pertence de forma intrínseca à sua pessoa (cf. Jr 3,12) "Eu sou misericordioso" (זָסִיד אִנְיר).

Maçaneiro também comenta sobre a misericórdia ao longo das Escrituras Judaicas:

4 SCHÖKEL, L. A. Dicionário Bíblico Hebraico-Português. São Paulo: Paulus, 1997. p. 235.

5 LUCENA, M. C. P. M. T. R. De. A misericórdia de Deus nas palavras e na ação de Jesus. Dissertação de mestrado em estudos da religião. Lisboa: Universidade Católica Portuguesa, 2013. p. 3. 
O amor entranhado de Deus se dá a nós para gerar e regenerar a vida. Esta tem sido a experiência mais marcante do amor divino ao longo da Bíblia. Das Escrituras Judaicas recordamos: a teofania do Sinai, na qual Iahweh se declara "Deus de ternura e piedade, rico em graça e fidelidade" (Ex 34,6-9), o resgate da vida e da justiça pelo Ano da Graça (Lv 25), os salmos de perdão (Sl 6, 32, 38, 51, 103, 130, 143); o amor divino que conduz o Povo da Aliança (Sl 136); a consolação de Israel (Is 30,18-26; 35 e 40 inteiros); as obras de misericórdia em Is 58,3-12 e o hino ao Deus Amigo, jóia da literatura sapiencial (Sb 11,21-26). ${ }^{6}$

Contudo, como se pode conciliar a natureza intrínseca da misericórdia e pessoa de Deus com as diversas passagens no Antigo Testamento que demonstram sua ira e juízo sobre povos, cidades e indivíduos? Muitas vezes essa ira é explicitada através de guerras, pragas, juízos, enfermidades e outras ações de igual peso.

O Papa Francisco ${ }^{7}$ afirma que justiça e misericórdia não são dois aspectos em contraste entre si, mas dimensões de uma única realidade. Além disso, assevera que a misericórdia não é contrária à justiça e sim exprime o comportamento de Deus para com o pecador, oferecendo-lhe uma nova possibilidade de se arrepender, converter e acreditar (MV, 20; 21).

O profeta Jonas pode emblemática e curiosamente elucidar esta questão. O profeta é chamado para clamar contra a cidade de Nínive devido ao fato do pecado da cidade causar a ira de Deus (cf. Jn 1,2; 3,2 ). Após sua conhecida relutância, o profeta finalmente prega àquela cidade (cf. Jn 3,3-4). Como resultado da palavra profética houve imediato reconhecimento, arrependimento e esperança de todo aquele povo (cf. Jn 3,5-9). Deus então, diante da mudança de postura do povo também passa de uma atitude de ira para a de misericórdia (cf. Jn 3,10). De maneira avessa à ação divina o profeta declara que a razão de seu endurecimento em relação à sua missão era a ciência do caráter divino (cf. Jn 4,2). A narrativa termina com o questionamento do próprio Deus misericordioso ao profeta, se Ele não deveria demonstrar misericórdia diante do arrependimento (cf. Jn 4,9-11). Desta forma o exercício da misericórdia ou juízo de Deus geralmente caminham relacionando-se

6 MAÇANEIRO, M. Misericórdia, carisma e missão. I Congresso Apostólico Mundial da Misericórdia. Roma: WACOM, 2008. p. 3.

7 FRANSCISCO I. Misericordiae Vultus. O rosto da misericórdia. Bula de proclamação do Jubileu Extraordinário da Misericórdia. São Paulo: Paulus e Loyola, 2015. 
com a atitude do homem (cf. Ex 8,31-32; 32,7-14; 33,3-19; Nm 16,4150; 21,4-9; Dt 7,12-16; 11,26-28; 15,1-11; 20,10; 28,1-68; 30,1-20; Jz $2,10-19 ; 1 \mathrm{Cr} 30,8-10)$.

Também podemos destacar os chamados "Salmos de misericórdia" (S1 25,41-43, 51, 57, 92, 103, 119, 136). Não que estes sejam exclusivos sobre o tema, pois outros também mencionam a misericórdia divina ( $\mathrm{cf}$. Sl 145,8-9; 146,7-9; 147,11).

Pinto comenta sobre a natureza destes salmos:

A misericórdia é uma das características divinas que o Saltério coloca em destacada evidência. De fato, há poemas que podemos chamar de "Salmos da misericórdia", porque estão imbuídos pela ação amorosa do Senhor com a qual Ele se dirige aos seus fieis. A palavra "misericórdia" (hésed) tem uma forte riqueza de significados, e é traduzida de diversas maneira: ternura, graça, misericórdia, clemência, bondade, benevolência, amor. Este vocabulário revela um traço surpreendente de Deus: o da maternidade. Se há um lugar onde mora a hésed divina, é o ventre, as entranhas (rahamim): as entranhas maternais de Deus se comovem ao ponto de perdoar o grande pecado cometido (Is 49,15; Sl 103,13). No mundo bíblico, a parte mais íntima onde estão abrigados os sentimentos é precisamente o ventre, e isto cria uma forte proximidade entre a misericórdia e a geração: "dar a luz à misericórdia" equivale a "por a vida no mundo"s

Este mesmo autor ${ }^{9}$ também explica o Salmo 136 que repete por vinte e seis vezes a palavra hesed (ำ) que a maioria das traduções vertem para amor. Diz que o termo está presente em cada versículo, marcando o ritmo do poema: "toda a história da salvacão se reinterpreta à luz da misericórdia e da vontade amorosa de Deus de intervir em favor de seu povo, desde o princípio da criação até o dia de hoje”. Afirma que o propósito de recordar e de revisar o passado é, de fato, o de mostrar a ação divina em favor de seu povo, obtendo uma lição de fé e de esperança para o presente da comunidade.

8 PINTO, S. Os Salmos da misericórdia. Conselho Pontifício para a promoção da Nova Evangelização. São Paulo: Paulus, 2015. p. 7.

9 PINTO, S. Os Salmos da misericórdia. Conselho Pontifício para a promoção da Nova Evangelização. São Paulo: Paulus, 2015. p. 48. 
Wallis ${ }^{10}$ observa que este Deus "mostra seu amor misericordioso através de uma aliança com Israel. YHWH executa suas ações em benefício de seu povo fundamentado em sua aliança e promessas com o mesmo (cf. Dt 7,8; 10,15; Jr 31,3; Os 11,4)".

Nas Escrituras de Israel fica patente que o povo de Deus sempre está aquém de Sua bondade e cuidado. Mesmo assim, este povo deve dar-se à prática da misericórdia na relação com o seu próximo, devendo manifestar para com ele a bondade que experimentou da parte de Deus. O Deus misericordioso demanda dos que nele acreditam que também pratiquem a misericórdia para com os seus semelhantes (cf. Ex 23,9; Mq 6,8; Zc 7, 9-10).

\section{A misericórdia de Deus explicitada no Quarto Evangelho}

Através dos sinóticos fica evidenciada a atitude de misericórdia de Deus em Cristo (cf. Mt 5,7; 9,35-36; Mc 1,40-41; Lc 4,18-19; 7,22; $10,30-37 ; 15,11-32 ; 18,9-14)$. Mas é no Quarto Evangelho que fica exponencialmente declarado que Cristo é aquele que realiza as obras de seu Pai (cf. Jo 5,20.36; 9,4; 10,25.32.37-38; 14,10).

Pereira comenta sobre o paralelo da hesed (ำ,) do Antigo Testamento ecoada na vida e ministério de Jesus no Quarto Evangelho:

João não usa o termo éleos em seu evangelho, praticamente substituindo- o por agápe, "amor", ou, excepcionalmente, como na sintese do prólogo, em 1,14, por cháris, "graça". De fato, a hendiade do Lógos "cheio de graça e de verdade", gr. plêres xáritos kai aletheias, corresponde à hendíade de YHWH, "rico em misericórdia e fidelidade", hebr. râb hesed we'emeth, gr. Poluéleos kai alêthinós, no texto da revelação a Moisés (Ex 34,6). Afinal, na $1^{a}$ carta, a hendíade será substituida pelo simples substantivo agápe - amor oblativo, amor que se doa - na suprema definição do ser de Deus: Deus é Amor (1Jo 4,8.16). E assim, o Deus que é hesed, misericórdia, e que quer de nós o hesed inter-humano (Os 6,6), Ele, que é agápe, amor, quer de nós, no "único mandamento" de

10 WALLIS, H. G. in BOTTERWECK, G. J.; RINGGREN, H. Verbete ahab. Theological Dictionary of the Old Testamet. Vol. I. Grand Rapids: W. B. Eerdmans Publishing Company, 1986. p. 111-116. 
seu Filho, que pratiquemos o agápe inter-humano, o amor fraterno (Jo $13,34$ e 15,12$).{ }^{11}$

No Quarto Evangelho, este conceito do ministério do Cristo é salientado de maneira ainda mais enfática do que nos sinóticos. O termo

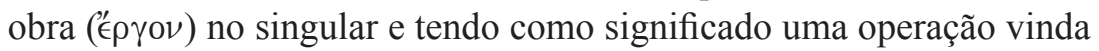
de Deus aparece cinco vezes (cf. Jo 4,34; 6,29; 7,21; 10,33; 17,4). Já o vocábulo no plural, obras ('́ $\rho \gamma \alpha)$ tem uma ocorrência ainda maior, vinte vezes, sendo que em quinze vezes novamente se dá a apresentação do conceito de obras como advindas de Deus (cf. Jo 5,20.36; 6,28; 7,3; 9,4; $10,25.32 .37-38 ; 14,10)$.

Neste contexto de obras provenientes de Deus, o papa Franscisco ${ }^{12}$ conclama a Igreja a "anunciar a misericórdia de Deus à semelhança de Jesus, com linguagens e gestos com obras de misericórdia corporal e espiritual que pervadam as mais variadas periferias existenciais". Praticando desta forma o ser "misericordiosos como o Pai" (MV, 12; 14; 15).

Os sinais registrados no Quarto Evangelho têm o propósito específico e declarado de gerar fé em Cristo e em Deus e que esta leve à vida aquele que crê (cf. Jo 20,30-31) e não somente uma fé temporária e pautada na dependência mais dos milagres em si do que em seu autor, o Cristo (cf. Jo 2,23-25).

Pode-se concordar com as definições iniciais de Thompson sobre a natureza dos sinais de Cristo e sua identificação com a pessoa de Deus.

Um sinal em João é uma manifestação, através da pessoa de Jesus, da obra de Deus no mundo...Seu significado não deve ser categorizado como algo de significado somente "espiritual" como às vezes é proposto, porque eles são feitos reais que acontecem entre pessoas reais. Isto quer dizer que os sinais são a obra de Deus e manifestam o verdadeiro caráter, ou algum aspecto do caráter de Deus (5:19-21,36; 6:32; 9:3,33; 10:25,32,37-38; 14:8-11; 15:24). Um sinal é uma manifestação, através da pessoa de Jesus, da obra de Deus no mundo. ${ }^{13}$

11 PEREIRA, N. B. Misericóridia, amor, bondade. A misericórdia que Deus quer. São Leopoldo: UNISINOS, Cadernos Teologia Pública, Ano XII, vol. 12, n. 105, 2015.

12 FRANCISCO I. Misericordiae Vultus. O rosto da misericórdia. Bula de proclamação do Jubileu Extraordinário da Misericórdia. São Paulo: Paulus e Loyola, 2015.

13 THOMPSON, M. M. Signs and Faith in the Fourth Gospel. Princeton: IBR vol 1, 1991, p. 89-108. Tradução minha. Curiosamente neste artigo esta autora tenta contraditar que os sinais têm um caráter mais espiritual, mas à medida que avança em seu estudo ela parece fortalecer cada vez mais os argumentos que quer refutar. 
O Quarto Evangelho relata de forma hiperbólica a grande quantidade dos milagres realizados por Jesus (cf. Jo 21,25). Em contrapartida, João descreve somente oito destes sinais, sete realizados antes da cruz. Como já citado anteriormente, o propósito destes sinais é a atestação da identidade e autoridade do Cristo bem como dar uma mostra do caminho verdadeiro para o Pai (cf. Jo 20,30-31).

À medida que os sinais vão sendo descritos neste Evangelho pode-se notar dentre vários elementos, não somente a grandiosidade e sobrenaturalidade dos sinais, mas também a atitude de Jesus na realização dos mesmos.

\section{João 2,1-11}

A transformação da água em vinho é chamada de início dos sinais de Jesus (cf. Jo 2,11). O v. 3 aponta para uma situação vexatória. Entre algumas possibilidades, ou aquele casal calculou mal o número total dos convidados, o que seria uma vergonha para a família, ou simplesmente eles eram pobres e assumiram o risco da vergonha devido à sua condição social.

Os versículos 4-7 descrevem a misericórdia do Pai concretizada em Jesus em uma sequência paradoxal que vai desde "A minha hora ainda não chegou" até o enchimento de talhas enormes com uma quantidade de longe sobressalente ao problema da festa. O melhor vinho foi servido para aqueles convidados em Caná sob a autoridade e misericórdia de Cristo. Testifica-se o encontro da misericórdia e provisão divinas.

\section{João 4,43-54}

O segundo sinal é a cura do filho de um nobre oficial e novamente o fato ou ao menos o encontro com Jesus acontece novamente em Caná (v. 46), visto que o milagre foi realizado à distância.

Aquele oficial suplica a Jesus (v. 47) e na verdade se desespera diante da terrível possibilidade da perda de seu filho (v. 49). Novamente aquilo que na narrativa parece ser uma dura reprimenda (v. 48) e com contornos de negativa, paradoxalmente passa para uma palavra de cura miraculosa (v. 50.53). 
Aquele homem confiou na palavra de Jesus. Mais uma vez o rosto de Cristo é o rosto do Pai que vê e escuta com misericórdia o clamor do aflito. Observa-se no relato o encontro entre a misericóridia e a fé.

\section{João 5,1-14}

A cura do paralítico no tanque de Jerusalém retrata a misericórdia de Cristo exercida para alguém excluído e por muito tempo, alguém sem auxílio, na periferia existencial. Este paralítico não avança na fila circunstancial (v. 7).

A misericórdia de Jesus é exercida com o rosto do Pai que nota, que vê e que toma a iniciativa: "Queres tu seres curado?" (v. 6 e 8). O mesmo Cristo exerce a misericórdia espiritual e corporal através da cura, do perdão e também da exortação contra o pecado (v. 14).

\section{João 6,1-14}

Novamente a misericórdia de Jesus é demonstrada na multiplicação dos pães e peixes. Cristo deixa-se ser condescendente por ora com muitos que o seguiam não devido à sua doutrina e sim devido somente aos sinais (v. 1). Jesus mais uma vez toma a iniciativa diante da necessidade evidente (v. 5).

Mais uma vez a misericórdia de Deus se traduz em provisão sobreexcelente e participação ativa (v. 11-13). A partilha material na perícope tanto é uma exortação viva da prática da misericórdia quanto também aponta mais uma vez para a identidade e autoridade do Cristo.

\section{João 6,16-21}

A misericórdia de Jesus é demonstrada nesta passagem em que Jesus traz paz. Os discípulos estavam em alto mar e Cristo não estava com eles. João descreve o perigo da situação registrando o esforço continuado do remar dos discípulos diante da agitação de um forte vento (v. 18-19). O texto paralelo no Evangelho de Marcos descreve que Jesus os viu com dificuldade de remar com o vento contrário (cf. Mc 6,47-48). A misericórdia é demonstrada no Deus encarnado que anda sobre o mar agitado, o principal problema daqueles discípulos e afirma sua autoridade (v. 20). O temor é desvanecido diante do "Eu sou" que entra no barco. 


\section{João 9,1-41}

Diante de um cego surge uma argumentação entre Jesus e seus discípulos. A dúvida era teológica, os discípulos queriam ser ensinados pelo Rabi, algo que era frequente em seu ministério. A resposta poderia transitar desde Moisés até os profetas, tecendo raciocínios sobre continuidades e descontinuidades dos efeitos dos pecados de uma geração para outras. Inusitadamente, Cristo encerra brevemente a discussão e passa para a ação. O Cristo misericordioso de maneira peculiar age na vida daquele cego (v.6-7). Aquele homem passaria de mendigo e alvo de especulação teológica (v. 1.8) para alguém que argumentaria teologicamente com os fariseus! (v. 24-34).

Cristo demonstra ainda misericórdia nesta passagem não somente na cura física, a obra material, mas também que ao saber da expulsão do outrora cego por parte dos fariseus, volta-se de seus afazeres mais uma vez a este; desta vez para realizar a obra espiritual da fé (v.35-38).

\section{João 11,1-44}

A perícope da ressurreição de Lázaro é a mais longa dentre os sinais no relato joanino. A passagem como um todo ressalta sucessivamente a misericórdia do Cristo. De maneira inequívoca, o evangelista afirma que Cristo amava aqueles irmãos (cf. v. 5). Também demonstra este amor retornando para a Judeia a despeito de ser alvo de perseguição ali e ser desencorajado pelos seus discípulos (v. 8.16).

Na sequência Jesus demonstra seu amor leal diante das palavras de Marta e Maria "se estivesses aqui, meu irmão não teria morrido" (v. 21.32), e este amor também acaba resultando em fé (v. 23-28).

O Cristo revela o rosto da misericórdia quando, diante da miséria humana face a sua finitude, se comove profundamente e também chora (v. 33-35). A misericórdia enfim é concretizada na própria ressurreição de Lázaro (v. 43-44).

\section{Conclusão}

O Quarto Evangelho apresenta sinais do Cristo misericordioso. Nestes sinais notada e reiteramente observa-se em Jesus a tradução encarnada da hesed (חסֶ) do Pai. O Cristo realiza as obras corporais e 
espirituais diante dos marginalizados. Estes são supridos em suas necessidades evidentes mas principalmente são chamados à fé salvívica.

Os sinais são realizados pontualmente, salientando de maneira cabal as obras sobrenaturais do Deus encarnado. O propósito dos sinais é o de gerar fé na identidade e autoridade do Filho de Deus (cf. Jo 20,31). O propósito é mostrar o caminho para o Pai (cf. Jo 14,6).

No desempenho destes sinais Jesus revela através de sua atitude e engajamento o rosto da misericórdia. Em alguns destes sinais o Cristo interage com os participantes, seja os discípulos seja os receptores dos sinais. Demanda deles atos de fé e participação. Ele dá o exemplo sendo como seu Pai misericordioso e é isto que demanda de seus seguidores, ou seja o ser "misericordiosos como o Pai".

\section{Referências bibliográficas}

CONFERÊNCIA DO EPISCOPADO LATINO-AMERICANO. Conclusões de Medellin. 4. ed. São Paulo: Paulinas, 1979.

ESSER, H. H. Misericórdia. Em BROWN, C.; COENEN, L. (Orgs). Dicionário Internacional de Teologia do NT. V. III. São Paulo: Vida Nova, 1985.

FRANSCISCO I. Misericordiae Vultus. O rosto da misericórdia. Bula de proclamação do Jubileu Extraordinário da Misericórdia. São Paulo: Paulus; Loyola, 2015.

GIRDLESTONE, R. B. Synonyms of the Old Testament. Grand Rapids: W. B. Eerdmans Publishing Company, 1986.

LUCENA, M. C. P. M. T. R. De. A misericórdia de Deus nas palavras e na ação de Jesus. Dissertação de mestrado em estudos da religião. Lisboa: Universidade Católica Portuguesa, 2013.

MAÇANEIRO, M. Misericórdia, carisma e missão. I Congresso Apostólico Mundial da Misericórdia. Roma: WACOM, 2008.

PEREIRA, N. B. Misericóridia, amor, bondade. A misericórdia que Deus quer. São Leopoldo: UNISINOS, Cadernos Teologia Pública, Ano XII, vol. 12, n. 105, 2015.

PINTO, S. Os Salmos da misericórdia. Conselho Pontifício para a promoção da Nova Evangelização. São Paulo: Paulus, 2015. 
SCHÖKEL, L. A.. Dicionário Bíblico Hebraico-Português. São Paulo: Paulus, 1997.

THOMPSON, M. M. Signs and Faith in the Fourth Gospel. Princeton: IBR. Vol. 1, 1991.

WALLIS, H. G. in BOTTERWECK, G. J.; RINGGREN, H. Verbete ahab. Theological Dictionary of the Old Testamet. Vol. I. Grand Rapids: W. B. Eerdmans Publishing Company, 1986. 